\title{
Fasting plasma zeaxanthin response to Fructus barbarum L. (wolfberry; Kei Tze) in a food-based human supplementation trial
}

\author{
Chung Yuen Cheng, Wai Yuen Chung, Yim Tong Szeto and Iris F. F. Benzie* \\ Antioxidant Research Group, Faculty of Health \& Social Sciences, The Hong Kong Polytechnic University, Kowloon, Hong Kong SAR, \\ China
}

(Received 10 May 2004 - Revised 9 August 2004 - Accepted 1 September 2004)

\begin{abstract}
Age-related macular degeneration (AMD) is a common disorder that causes irreversible loss of central vision. Increased intake of foods containing zeaxanthin may be effective in preventing AMD because the macula accumulates zeaxanthin and lutein, oxygenated carotenoids with antioxidant and blue lightabsorbing properties. Lycium barbarum L. is a small red berry known as Fructus lycii and wolfberry in the West, and Kei Tze and Gou Qi Zi in Asia. Wolfberry is rich in zeaxanthin dipalmitate, and is valued in Chinese culture for being good for vision. The aim of this study, which was a single-blinded, placebo-controlled, human intervention trial of parallel design, was to provide data on how fasting plasma zeaxanthin concentration changes as a result of dietary supplementation with whole wolfberries. Fasting blood was collected from healthy, consenting subjects; fourteen subjects took 15 g/d wolfberry (estimated to contain almost $3 \mathrm{mg}$ zeaxanthin) for $28 \mathrm{~d}$. Repeat fasting blood was collected on day 29. Age- and sex-matched controls ( $n$ 13) took no wolfberry. Responses in the two groups were compared using the Mann-Whitney test. After supplementation, plasma zeaxanthin increased 2.5-fold: mean values on day 1 and 29 were 0.038 (SEM 0.003) and 0.096 (SEM 0.009) $\mu \mathrm{mol} / 1(P<0.01$ ), respectively, for the supplementation group; and 0.038 (SEM 0.003 ) and 0.043 (SEM 0.003) $\mu \mathrm{mol} / 1(P>0.05)$, respectively, for the control group. This human supplementation trial shows that zeaxanthin in whole wolfberries is bioavailable and that intake of a modest daily amount markedly increases fasting plasma zeaxanthin levels. These new data will support further study of dietary strategies to maintain macular pigment density.
\end{abstract}

Macular pigment: AMD: Zeaxanthin: Lutein: Fructus lycii: Kei Tze: Wolfberry: Antioxidant: Oxidative stress

Zeaxanthin is an oxygenated carotenoid (xanthophyll), and a structural isomer of lutein (Edge et al. 1997; Moeller et al. 2000; Krinsky et al. 2003). Both zeaxanthin and lutein are concentrated in the fovea, or 'yellow spot', of the eye, and constitute the macular pigment (Landrum \& Bone, 2001). In humans, zeaxanthin is located primarily in the central area of the macula, and lutein is found more peripherally (Landrum et al. 1999; Bone et al. 2000). Thinning of the macular pigment is a common accompaniment to ageing, and is associated with irretrievable loss of central vision, a condition known as age-related macular degeneration (AMD; Beatty et al. 1999; Landrum \& Bone, 2001; Hyman \& Neborsky, 2002). Currently there is no effective treatment for AMD, which is the leading cause of blindness in those aged $>65$ years (Stokkermans, 2000; Landrum \& Bone, 2001).

The underlying causes of AMD are poorly understood, but it is believed that oxidative damage to the lipid-rich retina owing to loss of the protective macular pigment is a key factor (Beatty et al. 2000; Landrum \& Bone, 2001). The antioxidant properties of lutein and zeaxanthin, along with their ability to absorb blue light, are believed to protect the retina from photo-oxidative damage, reduce light scatter within the eye, and thus maintain visual acuity (Hammond et al. 2001; Landrum \& Bone, 2001; Benzie, 2003; Krinsky et al. 2003; Mozaffarieh et al. 2003). Therefore, enhancement of macular pigment by increased dietary intake of carotenoids is a suggested strategy to delay or prevent AMD and enhance visual function (Hammond et al. 1997; Landrum et al. 1997; Moeller et al. 2000; Stokkermans, 2000). In this regard, lutein has been the focus of several supplementation studies (Landrum et al. 1997; Olmedilla et al. 2001; Bartlett \& Eperjesi, 2003; Bone et al. 2003). However, the potential benefit of increased intake of zeaxanthin may be greater than that of lutein, owing to the more centrally located foveal accumulation of zeaxanthin.

The small red berry known variously as Fructus lycii, wolfberry, Kei Tze and Gou Qi $\mathrm{Zi}$ is the dried, ripe fruit of the plant Lycium barbarum L. Wolfberry is rich in zeaxanthin, around $90 \%$ of which is in the form of the ester, zeaxanthin dipalmitate (Lam \& But, 1999; Zhou et al. 1999; Weller \& Breithaupt, 2003). Wolfberry is similar in texture and size to a raisin, and is commonly consumed in China for its pleasant flavour and because of its strong reputation in Chinese culture for being beneficial for vision. The dried berries can be chewed and eaten without further processing, but common practice is to add them to teas, soups and stews. There are no published reports of which we are aware that describe toxic effects or allergic reactions to ingestion of wolfberry.

To date, published studies of plasma zeaxanthin response to supplementation have used purified zeaxanthin or extracts of 
wolfberry (Leung et al. 2001; Bone et al. 2003; Breithaupt et al. 2004; Hartmann et al. 2004). Leung et al. (2001) showed that 6 weeks' supplementation of monkeys ( $n$ 3) with a wolfberry extract increased both their plasma and macular zeaxanthin content. Two recently published human trials focused on absorption kinetics of zeaxanthin, one after repeated oral doses of purified, free zeaxanthin (Hartmann et al. 2004), and the other on comparing absorption kinetics after a single oral dose of zeaxanthin, extracted from wolfberry, in its free or esterified form (Breithaupt et al. 2004). The only food-based human supplementation study we are aware of used egg yolk (Handleman et al. 1999). However, ingestion of eggs has the disadvantage of increasing LDL-cholesterol, thereby increasing coronary heart disease risk. Therefore, plasma zeaxanthin in human subjects after dietary supplementation with a natural, cholesterol-free food is of interest. This was the main focus of this study, in which response to 28-d supplementation with wolfberry was determined in a controlled, human intervention trial.

\section{Methods and materials}

This study had the approval of the Ethics Committee of The Hong Kong Polytechnic University, and all procedures involving human subjects complied with the Declaration of Helsinki, as revised in 2000

This was a single-blinded, placebo-controlled, human intervention trial of $28 \mathrm{~d}$ duration and of parallel design. A total of twentyseven apparently healthy Chinese adults were recruited with their informed consent. The age range of the subjects was $18-48$ years (mean 27.6 (SD 9.5)). BMI of volunteers ranged from of 17.9 to $24.7 \mathrm{~kg} / \mathrm{m}^{2}$ (mean $20 \cdot 8$ (SD 2.2)). Inclusion criteria included that subjects did not smoke, were not obese, and had no history of glaucoma, cataract, age-related macular degeneration or other retinal diseases. Subjects were excluded if they took regular antioxidant or carotenoid-rich supplements or had a history of serious or chronic disease. Subjects were allocated, on a non-selective basis, but stratified for age and BMI, to the control group ( $n$ 13 ; no supplement) or the study group $(n 14 ; 15 \mathrm{~g} / \mathrm{d}$ commercially available heat-dried wolfberries ('Rich Nature' brand, kindly supplied by Rich Nature Nutraceutical Labs Inc., Lynwood, USA). Each volunteer in the study group was provided with a 14-d supply $(210 \mathrm{~g})$ of wolfberry, along with instructions on how to prepare their daily supplement. The method of preparation adopted in this study was selected to mimic common usage, but in a standardised manner. In brief, two spoonfuls (a spoon of standard size was supplied) of the berries were added to one cup (around $250 \mathrm{ml}$ ) of boiling water and left to stand for around $15 \mathrm{~min}$. The softened berries were then mashed with the back of the spoon, and the berries and water were ingested. Volunteers were requested to take the berries in the evening, shortly after their evening meal. This time was chosen, and the berries fragmented, because carotenoids are more bioavailable in fragmented foods and if taken with fat (Hammond et al. 1997; Castenmiller \& West, 1998; Bone et al. 2000). For the control group, a cup of warm water was taken after dinner each evening for $28 \mathrm{~d}$. After $14 \mathrm{~d}$, members of the study group returned the berry container, and the remaining $14-\mathrm{d}$ supply $(210 \mathrm{~g})$ of berries was provided. Compliance was checked by regular telephone calls and e-mail contact, and by checking the contents of the returned container.

Fasting blood was collected, from the antecubital vein, into commercial heparinised blood collection tubes at baseline (day
1) and after $28 \mathrm{~d}$. Blood samples were kept at $4^{\circ} \mathrm{C}$ and in the dark until separation of plasma, which was within $3 \mathrm{~h}$ of collection. Plasma was aliquoted and immediately placed at $-70^{\circ} \mathrm{C}$. All plasma samples (days 1 and 29 from experimental and control groups) were run in the same batch to minimise analytical variation. Plasma lutein concentrations were also measured in these samples.

Zeaxanthin and lutein were measured simultaneously in extracted plasma using a reversed phase isocratic HPLC method. Pure zeaxanthin and lutein were purchased from Indofine Chemical Company Inc. (Hillsborough, NJ, USA), and purity was checked using HPLC (only one peak was found on the chromatogram of each; results not shown). Absolute ethanol, tetrahydrofuran and hexane (all Chromasolv for HPLC) were from Riedel-de Haen (Sigma-Aldrich Laborchemikalien $\mathrm{GmbH}$, Seelze, Germany), butylated hydroxytoluene (BHT) was from Sigma (St. Louis, MO, USA), ascorbic acid was from E. Merck (Darmstadt, Germany) and acetonitrile (HiperSolv for HPLC) was from BDH Laboratory Supplies (Poole, UK). Milli-Q water was used (Millipore Corp. Billerica, MA, USA). The chromatography system included an Alliance 2695 Separation Module with temperature-controlled column chamber and autosampler (Waters, Milford, MA, USA), Waters 2996 Photodiode Array Detector and Waters Empower Pro PDA software (version 5.00.00.00), a reversed-phase Luna $\mathrm{C}_{18}$ analytical column $(5 \mu \mathrm{m}, 250 \times 4.6 \mathrm{~mm}$ i.d.; Phenomenex, Torrance, CA, USA) and a cartridge guard column (Security Guard, $\mathrm{C}_{18}$, cartridge $4 \times 3.0 \mathrm{~mm}$ i.d., from Phenomenex). The mobile phase was $0.1 \%(\mathrm{w} / \mathrm{v})$ BHT in acetonitrile, which was filtered and degassed through a Millipore membrane (type $\mathrm{GV}$, pore size $0.22 \mu \mathrm{m}$, Millipore Corp.) before use. Detection was at $450 \mathrm{~nm}$. On the basis of preliminary work, the flow rate was time-programmed at two speeds, $1.0 \mathrm{ml} / \mathrm{min}$ for $0-12 \mathrm{~min}$ post-injection, and $2.5 \mathrm{ml} / \mathrm{min}$ for $12-60 \mathrm{~min}$. The columns worked under room temperature but the autosampler cooling chamber was at $4^{\circ} \mathrm{C}$.

Zeaxanthin and lutein are sensitive to light and oxygen. To minimise degradation, all procedures for preparing calibrators, controls and test samples were performed in dim light, and evaporation of extracts was under nitrogen. In addition, two antioxidants were added $(0.1 \% \mathrm{w} / \mathrm{v}$ ascorbic acid in aqueous phase and $0.1 \% \mathrm{w} / \mathrm{v}$ BHT in non-aqueous phase) to minimise oxidative losses during sample processing and analytical procedures, and aluminium foil was used to wrap sample containers to protect from direct illumination of light. Stock standards of pure zeaxanthin and lutein were prepared in $0.1 \%(\mathrm{w} / \mathrm{v})$ BHT in tetrahydrofuran. On the day of use, these were diluted in $0.1 \%(\mathrm{w} / \mathrm{v})$ BHT in ethanol and mixed, immediately prior to use, to provide working calibrators over the expected concentration range.

The extraction procedure was modified from that described by Aebischer et al. (1999). For calibrators, $200 \mu l$ of pooled heparinised plasma (in a $1.5 \times 10 \mathrm{~cm}$ glass, screw-capped test-tube) was firstly mixed with $200 \mu \mathrm{l}$ of Milli-Q water containing ascorbic acid $(0.1 \% \mathrm{w} / \mathrm{v})$. To this solution, $20 \mu \mathrm{l}$ of one of the calibrators and $380 \mu \mathrm{l}$ of $0.1 \%(\mathrm{w} / \mathrm{v})$ BHT-ethanol were added. The mixture was vortexed for $30 \mathrm{~s}$., following addition of $800 \mu \mathrm{l}$ of hexane containing BHT $(0.1 \% \mathrm{w} / \mathrm{v})$, the tubes (covered with aluminium foil) were placed on a horizontal mixer (Denley Spiramix 5; Denley Instruments Ltd, Billinghurst, UK) for $30 \mathrm{~min}$. The suspension was then centrifuged in a Jouan CR4-12 centrifuge (Jouan Ltd, France) at $2000 \mathrm{rpm}, 4^{\circ} \mathrm{C}$, for $10 \mathrm{~min}$. A $400 \mu \mathrm{l}$ aliquot of hexane (upper layer) containing the extracted zeaxanthin was 
withdrawn and evaporated to dryness at $\sim 40^{\circ} \mathrm{C}$ under a slow stream of nitrogen. The residue was then vortexed with $20 \mu \mathrm{l}$ of tetrahydrofuran (containing $0.1 \%$ w/v BHT), followed by addition of $80 \mu \mathrm{l}$ of mobile phase. The mixture was again vortexed to re-dissolve the residue. These extraction procedures were performed for all calibrators on the day of use. For extraction of test plasma or control, $200 \mu$ l of plasma or control (zeaxanthin-spiked pooled plasma) were mixed with $200 \mu l$ of $0.1 \%$ (w/v) ascorbic acid-water and $400 \mu \mathrm{l}$ of $0.1 \%$ (w/v) BHT-ethanol in the first step, with the rest of the extraction as above. Finally, $25 \mu 1$ of each extracted calibrator, sample or control was injected into the HPLC system. Peak areas of zeaxanthin and lutein were recorded from each chromatogram. By plotting the peak areas against concentrations, calibration curves were constructed. The concentration of each sample was calculated by dividing the peak area in the sample by the slope of the appropriate calibration curve.

The linear range was determined by direct injections of standards at various concentrations. Linearity of response was assessed from the coefficient of correlation $(r)$ of the regression line. Six replicates of each calibrator at various concentrations were used to assess within-day precision. The slopes from assays on $6 \mathrm{~d}$ (consecutive) were used to assess between-day precision. Precision was also assessed using separate extractions and injections of pooled plasma and pooled plasma spiked with zeaxanthin and lutein. To determine the limit of detection (LD), the signal to noise ratio limit was at least $2: 1$. The LD is the smallest amount that can be differentiated from zero, and was calculated as mean $+3 \mathrm{SD}$ of ten blank readings. For recovery studies, pooled plasma was spiked with zeaxanthin and lutein, and native ( $n$ 4) and spiked plasma samples $(n 4)$ were then extracted and assayed. By comparing results on samples with those obtained with direct injections of the same (spike) amounts of pure zeaxanthin and lutein ( $n 4$ each), recoveries were assessed.

Using this method, the peaks for lutein and zeaxanthin were well resolved, and both eluted within $12 \mathrm{~min}$ (Fig. 1). $\beta$-Carotene eluted very slowly, taking more than $2 \mathrm{~h}$ at a flow rate of $1.0 \mathrm{ml} /$ min to appear. As this $\beta$-carotene peak may interfere and overlap with peaks of interest in subsequent samples, sample injection intervals must be long enough to allow column washout. To avoid overly long injection intervals, the flow rate was programmed to increase to $2.5 \mathrm{ml} / \mathrm{min}$ once lutein and zeaxanthin had eluted (i.e. after $12 \mathrm{~min}$ ). With this setting, $\beta$-carotene eluted at around $55 \mathrm{~min}$, and the auto-injection interval was set to $60 \mathrm{~min}$, giving an acceptable throughput. Within-day coefficients of variation $(\mathrm{CVs})$ for zeaxanthin were $4 \%$ at $0.01 \mu \mathrm{mol} /$ 1 and $4 \%$ at $0.04 \mu \mathrm{mol} / 1(n$ 6): between-day CVs were $7 \%$ at $0.018 \mu \mathrm{mol} / \mathrm{l}$ and $6 \%$ at $0.03 \mu \mathrm{mol} / \mathrm{l}(n$ 6). Within-day CVs for lutein were $7 \%$ at $0.35 \mu \mathrm{mol} / 1$ and $3 \%$ at $0.87 \mu \mathrm{mol} / 1$ ( $n$ 6). Between-day CVs for lutein were $9 \%$ at $0.35 \mu \mathrm{mol} / \mathrm{l}$ and $5 \%$ at $0.70 \mu \mathrm{mol} / 1$ ( $n$ 6). Recovery of $0.009 \mathrm{nmol}$ zeaxanthin was 96.1\% ( $n$ 4). Dose-response for zeaxanthin is shown in Fig. 2. Linearity was maintained at least up to $1.75 \mu \mathrm{mol} / \mathrm{l}$ ( $r$ 0.9998) zeaxanthin. The LD was $0.5 \mathrm{pmol}$; under the assay conditions used this is equivalent to an LD of $0.0024 \mu \mathrm{mol} / 1$ for plasma zeaxanthin (also for lutein). The sensitivity of the analysis, or minimum detectable difference, was estimated based on the mean $+3 \mathrm{SD}$ of peak areas obtained by six replicate extractions and injections of pooled plasma, and was $0.0027 \mu \mathrm{mol} / 1$.

Carotenoids are carried in plasma within lipoproteins and are affected by lipid levels, therefore both total (as $\mu \mathrm{mol} / \mathrm{l}$ ) and lipid-standardised (as nmol zeaxanthin (or lutein) per mmol total cholesterol plus triacylglycerol) concentrations are presented. Plasma total cholesterol and triacylglycerol were measured using commercial test kit methods (Biosystems S.A., Spain) on a Cobas Fara centrifugal analyser (Roche, Basel, Switzerland).

To explore the dose of zeaxanthin supplied by the berries used in the supplementation study, a weighed sample of berries was extracted, zeaxanthin esters were hydrolysed and the total zeaxanthin content estimated by HPLC. Berries were homogenised in $0.5 \mathrm{ml}$ of $6 \mathrm{M}-\mathrm{NaOH}$, and $1 \mathrm{ml}$ of absolute ethanol containing $0.1 \%(\mathrm{w} / \mathrm{v})$ BHT was added. The mixture was sonicated for $3 \mathrm{~min}$, followed by incubation at $50^{\circ} \mathrm{C}$ for $3 \mathrm{~h}$ for hydrolysis of zeaxanthin esters, after which $0.5 \mathrm{ml}$ of $6 \mathrm{M}-\mathrm{HCl}$ was added and the $\mathrm{pH}$ of the mixture adjusted to 7 . Two $\mathrm{ml}$ of hexane containing $0.1 \%(\mathrm{w} / \mathrm{v})$ BHT was added for extraction of carotenoids, with mixing (on a Denley Spiramix 5) for $30 \mathrm{~min}$, after which the suspension was centrifuged in a Jouan CR4-12 centrifuge (Jouan Ltd) at $2000 \mathrm{rpm}, 4^{\circ} \mathrm{C}$, for $10 \mathrm{~min}$. One $\mathrm{ml}$ of the hexane layer was removed and evaporated to dryness under a stream of nitrogen at $40^{\circ} \mathrm{C}$. The residue was re-dissolved in $20 \mu \mathrm{l}$ of tetrahydrofuran containing $0.1 \%(\mathrm{w} / \mathrm{v}) \mathrm{BHT}$ and $80 \mu \mathrm{l}$ of $100 \%$ acetonitrile containing $0.1 \%(\mathrm{w} / \mathrm{v})$ BHT, and $5 \mu \mathrm{l}$ of the redissolved extract was injected into the HPLC system for determination of zeaxanthin and lutein. This procedure was performed once only, was not intended to be a definitive assessment of the zeaxanthin content of wolfberry, but aimed to furnish an approximation of the daily dose of zeaxanthin in the berries ingested.

For statistical analysis, Graphpad Prism was used (version 3.0, San Diego, USA). The pre-versus post- data were analysed using the Wilcoxon matched pairs test to compare data on days 1 and 29 for each subject. The Mann-Whitney test was used to compare responses to wolfberry and placebo; $P<0.05$ was considered significant.

\section{Results}

Demographic information on the control and study groups is summarised in Table 1. There were no significant differences in age, weight or BMI between the two groups. Day 29 samples were not available for three subjects in the control group, and for one subject in the study group; data are presented for ten control subjects and thirteen supplemented subjects.

The concentration of zeaxanthin (after hydrolysis) in the berries extracted was estimated at $194 \mu \mathrm{g} / \mathrm{g}$. Based on this, the $15 \mathrm{~g}$ supplement provided an additional dietary intake of zeaxanthin of approximately $3 \mathrm{mg} / \mathrm{day}$. The lutein content of the berries, which was measured at the same time as zeaxanthin, was much lower, at $5.8 \mu \mathrm{g} / \mathrm{g}$. Therefore the daily berry intake would have provided $<0.1 \mathrm{mg} / \mathrm{d}$ of additional lutein. After 28-d supplementation, the lutein concentration of fasting plasma had not changed significantly. However, there was a significant $(P<0 \cdot 01)$ and marked increase in both the total and the lipid-standardised plasma zeaxanthin concentrations (Table 2). One subject showed a poor response, with a pre-post difference of $0.007 \mu \mathrm{mol} / \mathrm{l}$ in plasma zeaxanthin. This subject had the highest pre-supplementation fasting plasma zeaxanthin concentration, but no significant correlation overall was seen between pre-supplementation plasma zeaxanthin concentrations and the magnitude of individual responses $(r-0.517 ; P>0.05)$. The data for this subject are included in Table 2. 

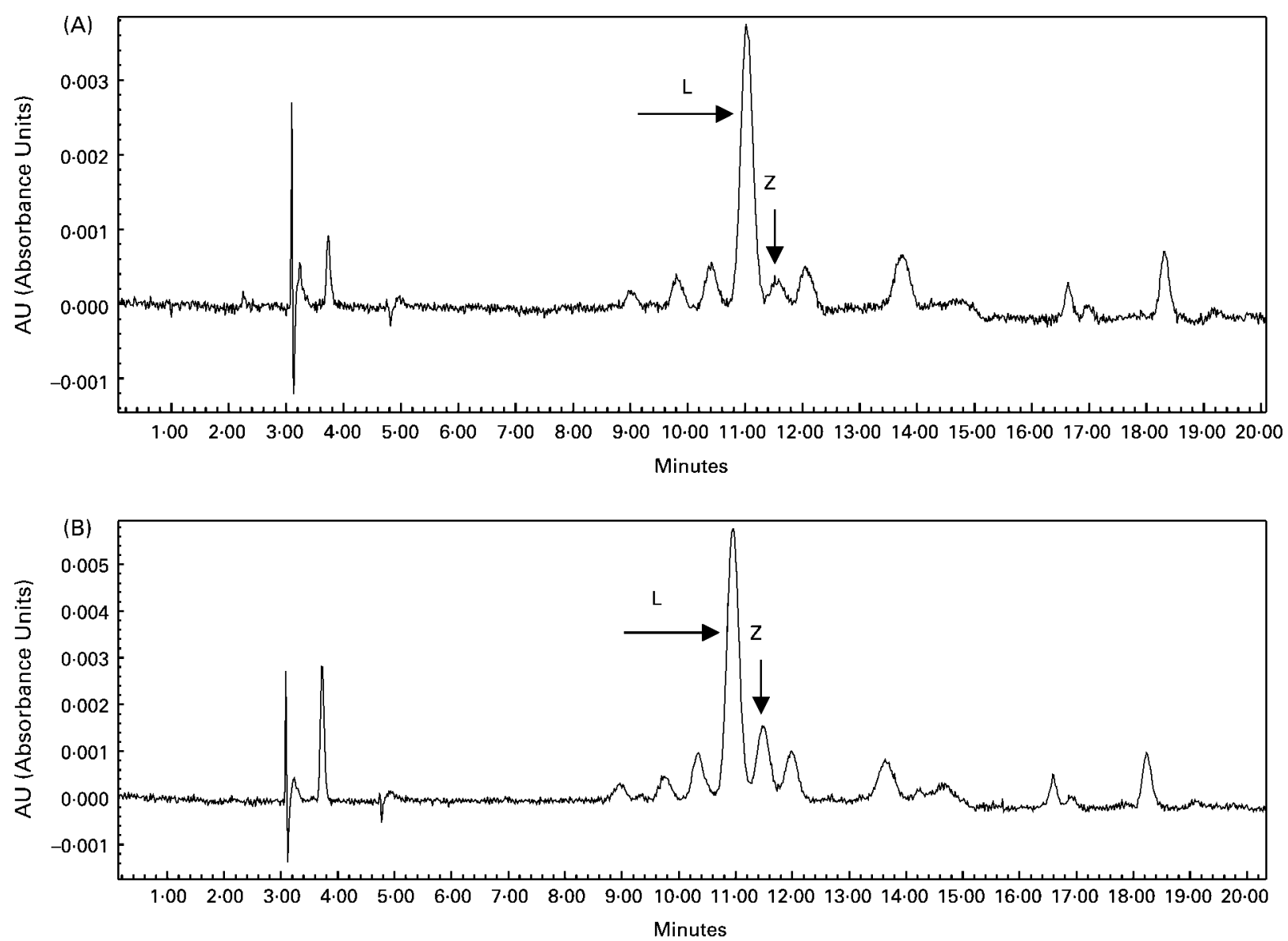

Fig. 1. Chromatogram of extracted plasma from a single volunteer, pre- (A) and post- (B) supplementation. Peaks of lutein (L) and zeaxanthin (Z) (identified by comparison with injection of pure lutein and zeaxanthin) are arrowed.

\section{Discussion}

The human diet is estimated to supply $1.3-3 \mathrm{mg} / \mathrm{d}$ of lutein and zeaxanthin combined (Sommerburg et al. 1998). However, as most xanthophyll-containing foods, such as corn, spinach, broccoli, orange and kiwi fruit, contain four to seven times more lutein than zeaxanthin, dietary zeaxanthin intake is usually low and fasting plasma levels of zeaxanthin are generally $<0.1 \mu \mathrm{mol} / \mathrm{l}$ (Bone et al. 2003; Breithaupt et al. 2004; Hartmann et al. 2004). To date, lutein has been the xanthophyll of interest in most AMD-related supplementation studies (Sommerburg et al.

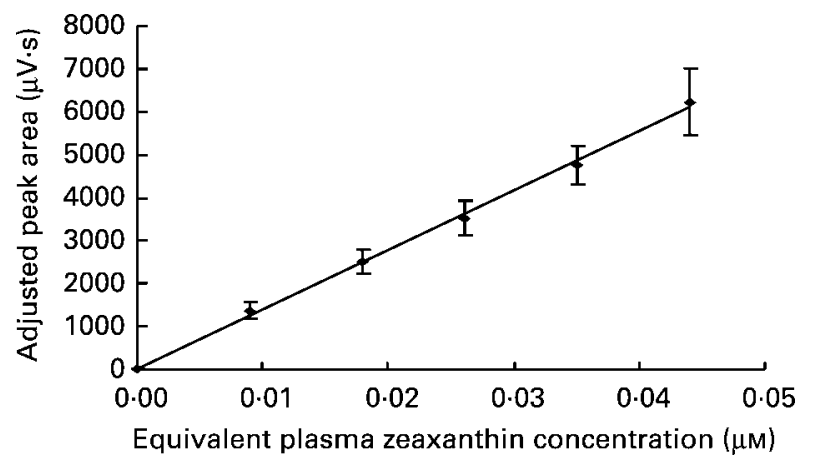

Fig. 2. Representative calibration curve for zeaxanthin: each point is mean of four readings (separate extractions) with \pm 2 SD error bars shown.
1998; Johnson et al. 2000; Landrum \& Bone, 2001; Bone et al. 2003). Data on plasma and macular pigment density changes following zeaxanthin supplementation are scarce, but are of interest in relation to the more specific accumulation of zeaxanthin in the central macula of humans (Bone et al. 2000).

The study of Hartmann et al. (2004) reported that fasting plasma zeaxanthin concentrations increased around 4-fold and 20 -fold, from an arithmetic mean of $0.05 \mu \mathrm{mol} / \mathrm{l}$ at baseline to a geometric mean of 0.20 and $0.92 \mu \mathrm{mol} / \mathrm{l}$ after 6 weeks of supplementation with, respectively, 1 and $10 \mathrm{mg} / \mathrm{d}$ of pure, synthetic, non-esterified zeaxanthin ( $n 10$ for each dose). Absorption kinetics were monitored for $24 \mathrm{~h}$ post-ingestion of both doses, and peak levels were seen at $10-15 \mathrm{~h}$. The $0-24 \mathrm{~h}$ area under the curve (AUC) for the $10 \mathrm{mg}$ dose was almost six times higher than that of the $1 \mathrm{mg}$ dose after a single dose and after 6 weeks of daily dosing, but individual responses were highly variable (Hartmann et al. 2004). Plasma levels reached $>90 \%$ of

Table 1. Demographics of study ( $n$ 14) and control ( $n$ 13) groups

\begin{tabular}{lccccc}
\hline & \multicolumn{2}{c}{ Study group } & & \multicolumn{2}{c}{ Control group } \\
\cline { 2 - 3 } & Mean & SEM & & Mean & SEM \\
\hline Age range (years) & $18-44$ & & & $18-48$ & \\
Age (years) & 28.0 & 2.68 & & 27.2 & 2.54 \\
Height $(\mathrm{m})$ & 1.59 & 0.016 & & 1.62 & 0.025 \\
Weight $(\mathrm{kg})$ & 51.39 & 1.76 & & 57.68 & 2.92 \\
\hline
\end{tabular}


steady-state concentration after around $17 \mathrm{~d}$ of supplementation, and levels decreased rapidly when the supplementation was stopped (Hartmann et al. 2004). This rapid decrease in plasma zeaxanthin after discontinuation of dosing was seen also by Bone et al. (2003), who reported plateau fasting levels of 0.56 and $0.48 \mu \mathrm{mol} / 1$ in each of two subjects who had been supplemented with $30 \mathrm{mg} / \mathrm{d}$ of crystalline, unesterified zeaxanthin for several weeks. This represented a 5-6-fold increase from baseline. In the study by Breithaupt et al. (2004), twelve subjects took (separately) two zeaxanthin-based extracts of wolfberry. Plasma levels after ingestion of both extracts plateaued at about $9 \mathrm{~h}$ post-ingestion, and the increase in plasma zeaxanthin averaged $0.02 \mu \mathrm{mol} / \mathrm{l}$ after the unesterified zeaxanthin extract, and about $0.06 \mu \mathrm{mol} / 1$ after ingestion of the same amount $(5 \mathrm{mg})$ of the esterified (dipalmitate) extract. The plasma zeaxanthin response in terms of $0-24 \mathrm{~h}$ AUC was significantly higher, but was also much more variable, following ingestion of the esterified extract, but the speed of response to both types appeared similar (Breithaupt et al. 2004). The authors suggested that the greater variation of response following ingestion of the esterified form may be due to variation in intestinal lipase activity, and that the dipalmitate form may be more bioavailable than the more polar, non-esterified form because of more effective micelle formation. It is of interest that no increase in plasma levels of zeaxanthin esters was seen following ingestion of the esterified form of zeaxanthin (Breithaupt et al. 2004).

In plant foods, zeaxanthin is found mainly in the esterified form (Lam \& But, 1999; Zhou et al. 1999; Krinsky et al. 2003; Weller \& Breithaupt, 2003). Zeaxanthin is found in relatively high concentration in egg yolk $(210 \mu \mathrm{g} / \mathrm{yolk})$, but this is mainly in the unesterified form. The petals of some flowers, such as marigold, are also a rich source of zeaxanthin $(500 \mu \mathrm{g} / 100 \mathrm{mg}$ ) (Handleman et al. 1999; Olmedilla et al. 2001). Marigold extracts are available as supplements, but flowers are not a common component of the human diet. Wolfberry is rich in zeaxanthin dipalmitate, but estimates of berry content vary depending on grade and source of the berries. Lam \& But (1999) reported a total zeaxanthin content of between 1.1 and $4.3 \mathrm{mg} / 100 \mathrm{~g}$, with an average of $2.4 \mathrm{mg} / 100 \mathrm{~g}$, in five different samples of wolfberry. Leung et al. (2001) stated that values of $30 \mathrm{mg} / 100 \mathrm{~g}$ have been found. Weller \& Breithaupt (2003) reported a much higher content $(82 \mathrm{mg} / 100 \mathrm{~g})$. We performed an exploratory study of zeaxanthin content of the berries used in this study and, based on the $19.4 \mathrm{mg} / 100 \mathrm{mg}$ found, estimate the dose supplied in the $15 \mathrm{~g}$ daily dose of berries to be around $3 \mathrm{mg}$ zeaxanthin.

Spinach and corn are also rich in lutein and zeaxanthin. However, increased intake of cooked spinach and corn did not lead to an increase in plasma zeaxanthin concentrations (Bone et al. 2000; Mozaffarieh et al. 2003). Clearly, the issue of bioavailability of zeaxanthin from different foods, as well as in different purified forms, is an important one. It is known that ingestion of fat is needed to facilitate absorption of carotenoids, and this may help explain the high bioavailability of zeaxanthin in egg yolk (Handleman et al. 1999). However, it is possible that zeaxanthin is less well absorbed and distributed than lutein (Castenmiller \& West, 1998; Bone et al. 2003). The study of Bone et al. (2003) showed that the relative change in plasma lutein was twice that of zeaxanthin in the same subject supplemented with $30 \mathrm{mg} / \mathrm{d}$ lutein and, separately, zeaxanthin, and the plateau supplementation-induced plasma zeaxanthin level was less than one-third that of lutein (Bone et al. 2003). However, as pointed out by the authors, the low response to zeaxanthin may have been due to differences in the formulations used, 
as the lutein used was esterified and the zeaxanthin was unesterified (Bone et al. 2003).

Increased intake of some zeaxanthin-rich foods does increase plasma zeaxanthin concentration. Supplementation with egg yolk was reported (Handleman et al. 1999) to increase plasma lutein and zeaxanthin by, respectively, $28 \%$ and $142 \%$. However, LDL-cholesterol increased also, by approximately $10 \%$. This increase is estimated to increase long-term heart disease risk by $14 \%$ in men with baseline cholesterol concentrations about $5.2 \mathrm{mmol} / \mathrm{l}$, the upper limit of the desirable range; the same increase in men with higher cholesterol concentrations would increase risk of heart disease to a greater extent (Verschuren et al. 1995). Therefore an egg yolk-based dietary strategy to increase plasma zeaxanthin cannot be recommended, and an alternative, cholesterol-free, food source is desirable. In this current study, we demonstrate a mean post-supplementation level of $0.096 \mu \mathrm{mol} / 1$, a $250 \%$ increase, in fasting plasma zeaxanthin after 4 weeks of supplementation with whole wolfberries estimated to supply $\sim 3 \mathrm{mg} / \mathrm{d}$ total zeaxanthin, more than is contained in a dozen egg yolks, and no deleterious effects on plasma lipids were seen (results not shown).

AMD is the leading cause of blindness in the elderly, is more common in smokers, and is associated with thinning of the macular pigment (Hyman \& Neborsky, 2002; Krinsky et al. 2003). There are observational data to support the link between increased intake of xanthophyll-rich foods and lower risk of AMD, but cause and effect relationships are still tenuous (Krinsky et al. 2003). It is believed that the beneficial effects of increased intake of lutein and zeaxanthin are mediated by increased macular pigment. A significant increase in macular pigment in association with increased plasma lutein has been reported in human subjects after 4 or more weeks of supplementation with lutein supplements or lutein-rich food, but not all studies find this (Hammond et al. 1997; Landrum et al. 1997; Sommerburg et al. 1998; Moeller et al. 2000; Mares-Perlman et al. 2002; Bartlett \& Eperjesi, 2003; Bone et al. 2003; Mozaffarieh et al. 2003). This may be owing to the type of supplement or food used, and to the duration of the dosing. It has been suggested also that there may be 'responders' and 'non-responders' to increased xanthophyll intake, and published data show very variable responses, both in time and magnitude (Hammond et al. 1997; Leung et al. 2001; Bone et al. 2003; Breithaupt et al. 2004; Hartmann et al. 2004). In the study by Leung et al. (2001), serum zeaxanthin and lutein concentrations in rhesus monkeys $(n 3)$ were measured before and after 6 weeks of supplementation with $2.2 \mathrm{mg}$ zeaxanthin/d in the form of a wolfberry extract. Serum zeaxanthin concentrations were reported to increase $2 \cdot 5$-fold compared with basal levels, and the average zeaxanthin content in the maculae of the treated animals was twice that of control animals. However, examination of the data (Leung et al. 2001) shows that one of the three animals fed an extract of wolfberry showed no increase in plasma zeaxanthin. Intriguingly, though having the lowest preand post-supplementation plasma zeaxanthin levels, this animal was shown to have the highest macular content of zeaxanthin at the end of the study. The significance of this finding is not clear. Furthermore, contrary to humans who accumulate zeaxanthin in the central area of the macula, the species used in the study, rhesus monkeys (Macaca mulatto), concentrate lutein centrally (Leung et al. 2001).

In human studies (Hammond et al. 1997; Landrum et al. 1997; Bone et al. 2003) increased macular pigment density has been reported with lutein and zeaxanthin supplementation. Interestingly, data from a small (n 2) human study of high-dose zeaxanthin supplementation $(30 \mathrm{mg} / \mathrm{d}$; Bone et al. 2003) showed that the increase in macular pigment lagged behind that in plasma zeaxanthin. Plateau plasma levels of zeaxanthin were seen after about 30 and $10 \mathrm{~d}$ of supplementation for the two subjects studied, but macular pigment did not begin to increase until 1-2 weeks after these times. However, thereafter the macular pigment increased in an approximately linear way. In the single subject who continued with supplementation to $120 \mathrm{~d}$, the macular pigment density plateaued at about 20 weeks after the

Table 3. Summary of human trials of fasting plasma response to zeaxanthin supplementation

\begin{tabular}{|c|c|c|c|c|}
\hline $\begin{array}{l}\text { Supplement type, dose } \\
\text { and duration }\end{array}$ & $n$ & $\begin{array}{l}\text { Post-supplementation fasting } \\
\text { plasma zeaxanthin in absolute } \\
(\mu \mathrm{mol} / \mathrm{l}) \text { and relative terms }\end{array}$ & Comment & Reference \\
\hline $\begin{array}{l}\text { Pure, synthetic, unesterified } \\
\text { zeaxanthin; } 1 \mathrm{mg} / \mathrm{d} \text { and } \\
10 \mathrm{mg} / \mathrm{d} \text { for } 42 \mathrm{~d}\end{array}$ & 10 & $\begin{array}{l}\text { Mean } 0.20(\mathrm{SD} 0.07) \\
\text { at } 1 \mathrm{mg} \text { dose } \\
(\times 4 \text { increase }) \text { and } \\
0.92(\mathrm{SD} 0.28) \text { at } 10 \mathrm{mg} \\
\text { dose }(\times 20 \text { increase })\end{array}$ & $\begin{array}{l}\text { Parallel study; } \\
\text { dose-response } \\
\text { seen }(\times 10 \text { dose } \\
\text { gave } \times 5 \text { response })\end{array}$ & Hartmann et al. (2004) \\
\hline $\begin{array}{l}\text { Crystalline, } \\
\text { unesterified zeaxanthin; } \\
30 \mathrm{mg} / \mathrm{d} \text { for } 60 \mathrm{~d} \text { (one } \\
\text { subject) and } 120 \mathrm{~d} \\
\text { (one subject) }\end{array}$ & 2 & $\begin{array}{l}\text { Individual values: } 0.48 \\
\quad(\times 5 \text { increase }) ; 0.56 \\
(\times 6 \text { increase })\end{array}$ & $\begin{array}{l}\text { Plateau reached for } \\
\text { one subject at } \sim 10 \mathrm{~d} ; \\
\sim 30 \mathrm{~d} \text { for the other; } \\
\text { zeaxanthin response } \\
\text { lower than to same } \\
\text { dose of esterified lutein }\end{array}$ & Bone et al. (2003) \\
\hline $\begin{array}{l}1.5 \text { egg yolks/d supplying } \\
\sim 280 \mu \mathrm{g} / \mathrm{d} \text { zeaxanthin } \\
(>90 \% \text { in unesterified form }) \\
\text { for } 32 \mathrm{~d}(4.5 \text { weeks })\end{array}$ & 11 & $\begin{array}{l}\text { Mean } 0.105(\text { SD } 0.023) \text { with } \\
\text { corn oil diet }(\times 2 \text { increase); } \\
0.116 \text { (SD } 0.027) \text { with beef } \\
\text { tallow diet }(\times 2.5 \text { increase })\end{array}$ & $\begin{array}{l}\text { Cross-over study; } \\
\text { zeaxanthin in egg } \\
\text { yolk highly bioavailable; } \\
8-11 \% \text { increases } \\
\text { seen in plasma LDL }\end{array}$ & Handleman et al. (1999) \\
\hline $\begin{array}{l}15 \mathrm{mg} / \mathrm{d} \text { wolfberries } \\
\text { for } 28 \mathrm{~d} \text {; whole berry } \\
\text { supplement estimated } \\
\text { to provide } \sim 3 \mathrm{mg} / \mathrm{d} \\
\text { esterified zeaxanthin }\end{array}$ & $\begin{array}{l}27 \text { (test } \\
\text { group, } n 14 ; \\
\text { control } \\
\text { group, } n 13 \text { ) }\end{array}$ & $\begin{array}{l}\text { Mean } 0.096 \text { (SD 0.034) } \\
(\times 2.5 \text { increase }) \\
\text { in test group }\end{array}$ & $\begin{array}{l}\text { Controlled intervention } \\
\text { trial; parallel design; } \\
\text { no significant correlation } \\
\text { seen between fasting } \\
\text { zeaxanthin at entry and } \\
\text { magnitude of response }\end{array}$ & This study \\
\hline
\end{tabular}


supplementation had begun. Interestingly, this was $20 \mathrm{~d}$ after supplementation was stopped, and when plasma levels had decreased to pre-supplementation levels. The speed of both plasma and macular changes in one of the subjects was faster than the other (Bone et al. 2003). Similar findings were reported for lutein (Landrum et al. 1997). This is congruent with the concept that plasma xanthophyll supply helps determine macular delivery and enrichment. It is interesting to note also that, while the plasma concentration decreased rapidly when supplementation was discontinued, the macular pigment was maintained at its higher, supplementation-related level for the following 4 months (Bone et al. 2003). The authors suggested that this could indicate that continued high-dose supplementation may not be necessary for maintenance of the macular pigment, and that an initial loading followed by a low maintenance dose may be adequate (Bone et al. 2003). The recent finding that the esterified form of zeaxanthin (zeaxanthin dipalmitate) induces a greater plasma response than the unesterified form (Breithaupt et al. 2004) suggests that the increases in macular pigment seen after $30 \mathrm{mg} / \mathrm{d}$ of unesterified zeaxanthin (Bone et al. 2003) could be induced by a smaller dose of esterified zeaxanthin. This remains to be confirmed.

When data from different studies were pooled, significant correlation was seen between the dosage of lutein and the plateau plasma concentration attained, and between this and the rate of increase in macular pigment density (Bone et al. 2003). For zeaxanthin, there is evidence that greater doses induce a greater plasma response (Hartmann et al. 2004), but individual response varies widely. At this time it does not appear that the magnitude of plasma response is determined or limited by the pre-existing plasma concentration per se. Data in relation to dose of zeaxanthin and plasma levels attained after a period of supplementation are summarised in Table 3. Insufficient data exist at this time to investigate correlation between increases in plasma zeaxanthin and macular pigment density response, and further work is needed in this area.

In conclusion, results of this controlled, food-based, supplementation trial show that short-term supplementation with a modest daily dose $(15 \mathrm{mg})$ of whole wolfberries taken in a similar way as in normal dietary practice markedly increased zeaxanthin in fasting plasma of healthy subjects. Therefore, wolfberry offers an inexpensive, effective and safe whole food dietary strategy to increase plasma zeaxanthin concentration. The implications for benefit of wolfberry intake in terms of ocular health are strong. Longer-term supplementation studies are now needed in regard to the potential for wolfberry to increase macular pigment density and help maintain visual acuity in our ageing population through its effect on plasma zeaxanthin concentration.

\section{Acknowledgements}

The authors are grateful to The Hong Kong Polytechnic University and The World Cancer Research Fund International for financial support for this work, and to Rich Nature Nutraceutical Labs Inc., Lynwood, USA for providing the wolfberries (Kei Tze). We are grateful also to the volunteers who participated in this study.

\section{References}

Aebischer CP, Schierle J \& Schüep W (1999) Simultaneous determination of retinol, tocopherols, carotene, lycopene, and xanthophylls in plasma by means of reversed-phase high-performance liquid chromatography. Methods Enzymol 299, 348-362.

Bartlett H \& Eperjesi F (2003) Age-related macular degeneration and nutritional supplementation: a review of randomized controlled trials. Ophthal Physiol Opt 23, 383-399.

Beatty S, Boulton M, Henson D, Koh HH \& Murray IJ (1999) Macular pigment and age related macular degeneration. Br J Ophthalmol 83, 867-877.

Beatty S, Koh H, Henson D \& Boulton M (2000) The role of oxidative stress in the pathogenesis of age-related macular. Surv Ophthalmol 45, $115-134$.

Benzie IFF (2003) Evolution of dietary antioxidants. J Comp Biochem Physiol 136, 113-126.

Bone RA, Landrum JT, Dixon Z, Chen Y \& Llerena CM (2000) Lutein and zeaxanthin in the eyes, serum and diet of human subjects. Exp Eye Res 71, 239-245.

Bone RA, Landrum JT, Guerra LH \& Ruiz CA (2003) Lutein and zeaxanthin dietary supplements raise macular pigment density and serum concentrations of these carotenoids in humans. J Nutr 133, 992-998.

Breithaupt DE, Weller P, Wolters M \& Hahn A (2004) Comparison of plasma responses in human subjects after the ingestion of $3 R, 3 R^{\prime}$-zeaxanthin dipalmitate from wolfberry (Lycium barbarum) and non-esterified $3 \mathrm{R}, 3 \mathrm{R}^{\prime}$-zeaxanthin using chiral high-performance liquid chromatography. Br J Nutr 91, 707-713.

Castenmiller JJM \& West CE (1998) Bioavailability and bioconversion of carotenoids. Ann Rev Nutr 18, 19-39.

Edge R, McGarvey DJ \& Truscott TG (1997) The carotenoids as anti-oxidants - a review. J Photochem Photobiol B 41, 189-200.

Hammond BR Jr, Johnson EJ, Russell RM, Krinsky NI, Yeum KJ, Edwards RB \& Snodderly DM (1997) Dietary modification of human macular pigment. Invest Opthalmol Vis Sci 38, 1795-1801.

Hammond BR Jr, Wooten BR \& Curran-Celentano J (2001) Carotenoids in the retina and lens: possible acute and chronic effects on human visual performance. Arch Biochem Biophys 385, 41-46.

Handleman GJ, Nightingale ZD, Lichenstein AH, Scaefer EJ \& Blumberg JB (1999) Lutein and zeaxanthin in plasma after dietary supplementation with egg yolk. Am J Clin Nutr 70, 247-251.

Hartmann D, Thurmann PA, Spitzer V, Schalch W, Manner B \& Cohn W (2004) Plasma kinetics of zeaxanthin and $3^{\prime}$-dehydro-lutein after multiple oral doses of synthetic zeaxanthin. Am J Clin Nutr 79, 410-417.

Hyman L \& Neborsky R (2002) Risk factors for age-related macular degeneration: an update. Curr Opin Ophthalmol 13, 171-175.

Johnson EJ, Hammond BR, Yeum KJ, Qin J, Wang XD, Castaneda C, Snodderly DM \& Russell RM (2000) Relation among serum and tissue concentrations of lutein and zeaxanthin and macular pigment density. Am J Clin Nutr 71, 1555-1562.

Krinsky NI, Landrum JT \& Bone RA (2003) Biologic mechanisms of the protective role of lutein and zeaxanthin in the eye. Annu Rev Nutr 23, $171-201$.

Lam KW \& But P (1999) The content of zeaxanthin in Gou Qi Zi, a potential health benefit to improve visual acuity. Food Chem 67, 173-176.

Landrum JT, Bone RA, Joa H, Kilburn MD, Moore LL \& Sprague KE (1997) A one year study of the macular pigment: the effect of 140 days of a lutein supplement. Exp Eye Res 65, 57-62.

Landrum JT, Bone RA, Moore LL \& Gomez CM (1999) Analysis of zeaxanthin distribution within individual human retinas. Methods Enzymol 299, 457-467.

Landrum JT \& Bone RA (2001) Lutein, zeaxanthin, and the macular pigment. Arch Biochem Biophys 385, 28-40.

Leung IYF, Tso MOM, Li WWY \& Lam TT (2001) Absorption and tissue distribution of zeaxanthin and lutein in rhesus monkeys after taking Fructus lycii(Gou Qi Zi) extract. Invest Ophthalmol Vis Sci 42, 466-471.

Mares-Perlman JA, Millen AE, Ficek TL \& Hankinson SE (2002) The 
body of evidence to support a protective role for lutein and zeaxanthin in delaying chronic disease: an overview. J Nutr 132, 518S-524S.

Moeller SM, Jacques PF \& Blumberg JB (2000) The potential role of dietary xanthophylls in cataract and age-related macular degeneration. $J$ Am Coll Nutr 19, Suppl., 522S-527S.

Mozaffarieh M, Sacu S \& Wedrich A (2003) The role of the carotenoids, lutein and zeaxanthin, in protecting against age-related macular degeneration: a review based on controversial evidence. Nutr J 2, 20-31.

Olmedilla B, Granado F, Bianco I, Vaquere M \& Cajigal C (2001) Lutein in patients with cataracts and age-related macular degeneration: a longterm supplementation study. J Sci Food Agric 81, 904-909.

Sommerburg O, Keunen JE, Bird AC \& van Kuijk FJ (1998) Fruits and vegetables that are sources for lutein and zeaxanthin: the macular pigment in human eyes. Br J Ophthalmol 82, 907-910.
Stokkermans TJW (2000) Treatment of age-related macular degeneration. Clin Eye Vis Care 12, 15-35.

Verschuren WM, Jacobs DR, Bloemberg BP, Kromhout D, Menotti A, Aravanis C, Blackburn H, Buzina R, Dontas AS \& Fidanza F (1995) Serum total cholesterol and long term coronary heart disease mortality in different cultures. Twenty-five-year follow-up of the Seven Countries Study. JAMA 274, 131-136.

Weller P \& Breithaupt DE (2003) Identification and quatification of zeaxanthin esters in plants using liquid chromatography-mass spectrometry. J Agric Food Chem 51, 7044-7049.

Zhou L, Leung I, Tso MOM \& Lam KW (1999) The identification of dipalmityl zeaxanthin as the major carotenoid in Gou Qi Zi by high pressure liquid chromatography and mass spectrometry. J Ocul Pharmacol Ther 15, 557-565. 